\title{
Study of Acid Hydrolysis on Organic Waste: Understanding The Effect of Delignification and Particle Size
}

\author{
Nadiem Anwar ${ }^{1, *}$, Iman Mukhaimin ${ }^{1}$, Mining Harsanti ${ }^{1}$, and Ate Romli ${ }^{1}$ \\ ${ }^{1}$ University of Jendral Achmad Yani, Chemical Engineering Department, Terusan Jendral Sudirman, Cimahi
}

\begin{abstract}
Organic wastes from Swiettenia marcophylla L, Artocarpus heterophyllus L, Mangifera indica L, and Annona muricata $L$ were prepared by grinding into $0.1875,0.3750,0.7500 \mathrm{~mm}$ of particle size and delignified by $2 \% \mathrm{NaOH}$ at $80^{\circ} \mathrm{C}$ for 90 minutes. Acid dilution hydrolysis process with $\mathrm{H} 2 \mathrm{SO} 41 \%$ was performed at $150^{\circ} \mathrm{C}$ for 120 minutes in a closed reactor. The effect of particle size and delignification on and reducing sugar concentration were investigated. The result showed (1) leaves that can be used as raw material to produce hydrogen should have 38$49 \%$ cellulose and hemicellulose. (2) Reducing sugar concentration increased with particle size reduction and delignification. (3) the best result with the highest reducing sugar concentration was achieved by $0.1875 \mathrm{~mm}$ particle size with delignification on Annona muricata L.
\end{abstract}

\section{Introduction}

The increasing energy demand, the decreasing production of crude oil, and the fluctuating crude oil prices have an impact on the economies of Indonesia. Similarly, The usage of fossil-based fuel has increased $\mathrm{CO}_{2}$ accumulation in the atmosphere that increased trigger global warming. Furthermore, there are significant interest and challenge to develop an alternative fuel that is affordable, renewable sources, and eco-friendly such as biomassbased energy.

Indonesia as a tropical country produced large amounts of biomass about 3.9 billion tons of dry plant biomass per year like agricultural waste, plantations, and forestry residues. The usage of agricultural waste, plantations, and forestry residues will minimize environmental impacts because they can be used as feedstocks for biofuel production or increase the valueadded chemical. Generally, hydrolysis process can convert dry plant biomass into reducing sugar in some ways, such as chemically [1], fermentatively [2], or enzymatically [3-6]. In previous research, Enzymatic hydrolysis of rice straw with pure or crude enzymes from Aspergillus niger and Trichoderma reesei, showed that hydrolysis in a batch process for seven hours more increased significantly reducing sugar concentration than the usage of commercial enzymes, but required time is too long [7]. This will be an obstacle to produce in large quantities. Anwar [8] has produced the same level reducing sugar concentration from rice straw by acid hydrolysis with a shorter time than enzymatic hydrolysis and it can be converted into hydrogen by the fermentation process.
Other plant biomass that has large quantities especially in University of Jendral Achmad Yani come from falling leaves of trees. The falling leaves have high lignocellulose concentration that can be converted into reducing sugar. Therefore, the utilization of falling leaves as biomass feedstock will be very potential and does not interfere sustainability of food crops

The lignocellulose concentration of plant biomass mainly consists of $40-50 \%$ cellulose, $25-30 \%$ hemicellulose, 15-20\% lignin, and traces of pectin, nitrogen compounds, and inorganic ingredients $[9,10]$. Cellulose is a polysaccharide with $\beta-1,4$-glucoside bonds in a linear chain. The $\beta-1,4$-glycoside bond on cellulose fibers can be hydrolyzed to produce glucose monomers by acid or enzymatic hydrolysis but the existence of lignin composition make the conversion lignocelluloses to energy is costly and ineffective up to now [2,11-15]. Besides that, differences of lignocelluloses composition make difference structure of biomass. Thus, it is necessary to design suitable pretreatment to break down the structure of biomass to improve the effectiveness of conversion.[16,17]

Prior to hydrolyzed, to increase reactivity in hydrolysis process and to break down cellulose crystallinity is necessary to remove lignin from the lignocellulose. Because lignin is a polymer formed through the phenylpropane units which have a function to rigidified cellulose microfibril and has physically bond with hemicellulose. Hemicellulose is a group low molecular weight of polysaccharide that can hydrolize into glucose, mannose, galactose, xylose, and arabinose. This step will increase reagent accessibility to polysaccharide in biomass [18-20]. Pretreatment is the

\footnotetext{
* Corresponding author: nadiemanwar20@yahoo.com
} 
important step to convert lignocelluloses to energy. It is necessary to separate the complex components of lignocellulose which consider the compatibility of feedstocks, enzymes, and organisms. The pretreatment process generally can be classified into physical [21], chemical [22], physical-chemical, biological methods and their combinations.

Krishnan [23] had given attention increasing the accessibility reagent to carbohydrates by chemical pretreatment, ammonia solution, adding ammonia solution had removed lignin and swelled the solid residue. Zhang [24] had pretreated lignocellulosic biomass using the synergistic effect of mechanical crushing and metal salts. Then compare both with different oxidation numbers on polymerization and crystallinity of biomass. $\mathrm{Yu}$ [25] had used an alkaline condition on softwood and hardwood to determine the effect of delignification methods on enzymatic hydrolysis of forest biomass. Both delignifications had improved enzymatic hydrolysis, especially for softwood.

J. Yoo [26] had compared the effect of two traditional methods using dilute acid (1\% sulfuric acid) and alkali ( $1 \%$ sodium hydroxide) and thermal mechanical extrusion pretreatment on the enzymatic hydrolysis of xylose from soybean. Pretreatment acid, alkali, and hot extrusion had successfully increased the xylose yield on the enzymatic hydrolysis by $69.6 \%, 128.7 \%$, and $132.2 \%$, respectively. Based on some previous research, alkali pretreatment is the best chemical pretreatment and important to remove lignin from biomass to increase the efficiency of hydrolysis process.

Current studies on pretreatment mainly focus on, identifying, evaluating, and understanding potential approaches on the effect of particle size and delignification, alkaline pretreatment, for subsequent acid hydrolysis with different feedstock biomass from falling leaves.

\section{Experimental}

\subsection{Material}

Plant biomass waste, Swietenia marcophylla L, Artocarpus heterophyllus L, Mangifera indica L, and Annona muricata L were collected from University of Jendral Achmad Yani. Natrium hydroxide $(\mathrm{NaOH})$, Sulfuric acid $\left(\mathrm{H}_{2} \mathrm{SO}_{4}\right)$, reducing sugar standard, Somogy I, Somogy II, and Nelson chemical reagents were of analytical grade.

\subsection{Preparation of feedstock}

\subsubsection{Reducing particle size}

The preparation methods for all the three feedstock was basically with an objective of reducing the particle size to increase the surface area of targeted reactions. Plant biomass waste, falling leaves, were prepared by cutting into $\pm 1 \mathrm{~cm}$, then dried under sunlight. Dried biomass was ground in an electric mixer to give a fine powder and screened into $0.1875,0.3750,0.7500 \mathrm{~mm}$ of particle size.

\subsubsection{Analysis of Cellulose and Lignin}

Analysis of lignin and cellulose followed the method of Chesson [32]. $1 \mathrm{~g}$ of dried biomass (a) and 150 $\mathrm{mL}$ of aquadest was heated in a water bath at a $90-100^{\circ} \mathrm{C}$ for 1 hour. The mixture filtered, washed, and dried until the weight was constant (b). The residue was added to $150 \mathrm{~mL}$ of $\mathrm{H}_{2} \mathrm{SO}_{4} 1 \mathrm{~N}$ and heated in the water bath at 90 $100^{\circ} \mathrm{C}$ for 1 hour. The mixture was filtered and washed with $300 \mathrm{~mL}$ of aquadest and then the residue was dried (c). The dried residue was soaked with $10 \mathrm{~mL} \mathrm{H}_{2} \mathrm{SO}_{4}$ at room temperature. After that, $150 \mathrm{~mL}$ of $1 \mathrm{~N} \mathrm{H}_{2} \mathrm{SO}_{4}$ was added to the mixture and refluxed in the water bath for 1 hour. The solid was washed with $400 \mathrm{~mL}$ of aquadest, heated in the oven at $105^{\circ} \mathrm{C}$ and weighed until the constant weight (d). Finally the solid was heated until becoming ash and weighted (e).The percentage of cellulose and lignin was calculated as follows:

$$
\begin{aligned}
& \% \text { cellulose }=\frac{c-d}{a} \times 100 \% \\
& \% \text { lignin }=\frac{d-c}{a} \times 100 \%
\end{aligned}
$$

where: $\mathrm{a}=$ sample weight $(\mathrm{g}), \mathrm{c}=$ the residue weight $(\mathrm{g})$ at the third weighing, $\mathrm{d}=$ the residue weight $(\mathrm{g})$ at the fourth weighing, $\mathrm{e}=$ the weight of ash $(\mathrm{g})$.

\subsection{Alkaline treatment.}

A $2500 \mathrm{~mL}$ beaker glass reactor was used for the delignification studies. A uniform suspension of the selected sample in distilled water with a by addition of $2 \% \mathrm{NaOH}$ at $80^{\circ} \mathrm{C}$ for 90 minutes in a batch-closed mixed flow reactor and the agitation was started using a mechanical stirrer. Before and after process weight of sample was determined to know the effect of chemical pretreatment on delignification,

\subsection{Acid Hydrolysis of lignocellulose}

Prior to hydrolysis process, organic wastes were divided into two types, with or without delignification. they were hydrolyzed using $1 \% \mathrm{H}_{2} \mathrm{SO}_{4}$ with a ratio of acid-biomass 1: 20 . The hydrolysis was performed $150^{\circ} \mathrm{C}, \mathrm{pH} 5.5$ for 120 minutes in a batch-closed reactor.

The reducing sugar was analyzed by Nelson-Somogy method with Uv-Vis Spectrophotometer. The schematic of Experimental can be seen in Fig. 1 


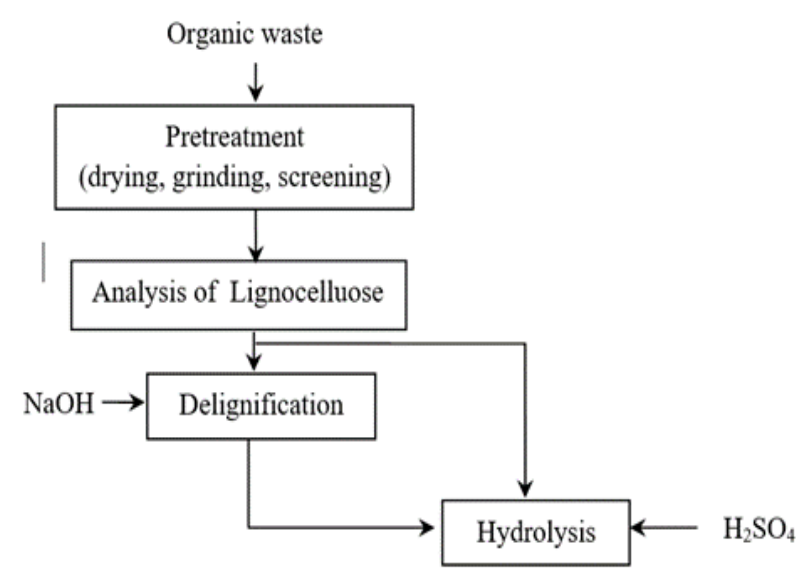

Fig. 1. The schematic of Experimental

\section{Result and discussion}

The following section analyzes the effect of particle size and delignification on hydrolysis process to produce reducing sugar. This research will compare with or without delignification treatment to produce reducing sugar concentration. The experimental results provide a basis data for the understanding of pretreatment biomass, which resulted in highest concentration of reducing sugar.

\subsection{The effect of feedstock type}

Different types of leaves as feedstock of had given effect on the process of hydrolysis. The effect was derived from lignocellulose content which is different from each leaf type. The result of lignocellulose analysis in Table 1. showed that leaves contained $14-15 \%$ cellulose, $21-35 \%$ hemicellulose, $17-29 \%$ lignin, with a total potential of the hydrolyzable component to produce reducing sugars such as glucose and xylose $38-49 \%$.

Table 1. the result of lignocellulose analysis

\begin{tabular}{|l|c|c|c|}
\hline \multicolumn{1}{|c|}{ Feedstock } & Cellulose & Hemicellulose & $\begin{array}{c}\text { Lignin }+ \\
\text { Ash }\end{array}$ \\
\hline $\begin{array}{l}\text { Swiettenia } \\
\text { marcophylla } \\
\text { L }\end{array}$ & $17 \%$ & $21 \%$ & $23 \%$ \\
\hline $\begin{array}{l}\text { Artocarpus } \\
\text { heterophyllus }\end{array}$ & $25 \%$ & $21 \%$ & $29 \%$ \\
L & $14 \%$ & $35 \%$ & $22 \%$ \\
\hline $\begin{array}{l}\text { Mangifera } \\
\text { indica L }\end{array}$ & $20 \%$ & $24 \%$ & $17 \%$ \\
\hline $\begin{array}{l}\text { Annona } \\
\text { muricata L }\end{array}$ & & & \\
\hline
\end{tabular}

Based on table 1, different types of leaves as a feedstock have different lignocellulose composition with cellulose content slightly smaller than lignin + ash. It makes the difference in characteristic leaf fiber, microfibril in the cell wall, pore structure on the cellulose surface and strong bond between cellulose, hemicellulose, and lignin in the crystallization zone than others[2]. In addition, these will increase the ability to block the accessibility reagent to cellulose and stability of cell walls.

Artocarpus Heterophyllus L has the highest lignin+ash content. Thus, it will need extra effort to degrade lignin. Because with highest lignin content, it will have the highest stability and ability to protect cellulose. Otherwise, Annona muricata L has the lowest lignin+ash content that makes more easily to degrade lignin from the feedstock. It is proved with some data on Tabel 2. that Annona muricata L has the highest weight loss after addition of $\mathrm{NaOH}$.

\subsection{The effect of delignification}

The result of lignocellulose analysis in Table 2 showed that decreasing particle size causes increasing weight loss from delignification results. A small particle will have larger contact surface area between $\mathrm{NaOH}$ and lignocellulose, thus solvent gives more chance to remove lignin. In addition, the weight loss after delignification is greater than the weight of previous lignin concentration. Based on weight loss after the delignification process, Annona muricata L is the highest, followed by Swiettenia marcophylla L, Mangifera indica L, and the last Artocarpus heterophyllus L. This showed that addition of alkali on biomass has removed some lignin from lignocellulose.

Tabel 2. The result of alkali pretreatment for delignification

\begin{tabular}{|c|c|c|c|}
\hline \multirow{2}{*}{ Feedstock } & \multirow{2}{*}{$\begin{array}{c}\text { Particle } \\
\text { size }\end{array}$} & \multicolumn{2}{|c|}{ Weight (gram) } \\
\cline { 3 - 4 } & $\begin{array}{c}\text { Before } \\
\text { delignification }\end{array}$ & $\begin{array}{c}\text { After } \\
\text { delignification }\end{array}$ \\
\hline \multirow{2}{*}{$\begin{array}{c}\text { Swiettenia } \\
\text { marcophylla } \\
\text { L }\end{array}$} & 0,7500 & 50.00 & 19.15 \\
\cline { 2 - 4 } & 0,3750 & 50.00 & 16.22 \\
\cline { 2 - 4 } & 0,1875 & 50.00 & 15.24 \\
\hline $\begin{array}{c}\text { Artocarpus } \\
\text { heterophyllus } \\
\text { L }\end{array}$ & 0,7500 & 50.00 & 30.79 \\
\cline { 2 - 4 } & 0,3750 & 50.00 & 22.26 \\
\cline { 2 - 4 } $\begin{array}{c}\text { Mangifera } \\
\text { indica L }\end{array}$ & 0,1875 & 50.00 & 20.06 \\
\cline { 2 - 4 } & 0,7500 & 50.00 & 23.49 \\
\cline { 2 - 4 } & 0,1875 & 50.00 & 23.17 \\
\hline \multirow{2}{*}{$\begin{array}{c}\text { Annona } \\
\text { muricata L }\end{array}$} & 0,7500 & 50.00 & 21.39 \\
\cline { 2 - 4 } & 0,3750 & 50.00 & 17.12 \\
\cline { 2 - 4 } & 0,1875 & 50.00 & 16.30 \\
\hline
\end{tabular}

The solubility of lignin in an alkali solution is the key to determine the effectiveness of alkali treatment by saponification reaction between inner molecules that will breakage the aryl ether linkages present in the lignin (contributing to about $50-70 \%$ of all the linkages) $[33,34]$. Consequently, the connecting bond lignocellulose will break and changes the pore structures, microstructure, macrostructure, chemical composition of and crystallinity of lignocellulose[2,35]. Tabel 2. Showed that the highest initial lignin content will give the highest weight feedstock after the delignification process. In other 


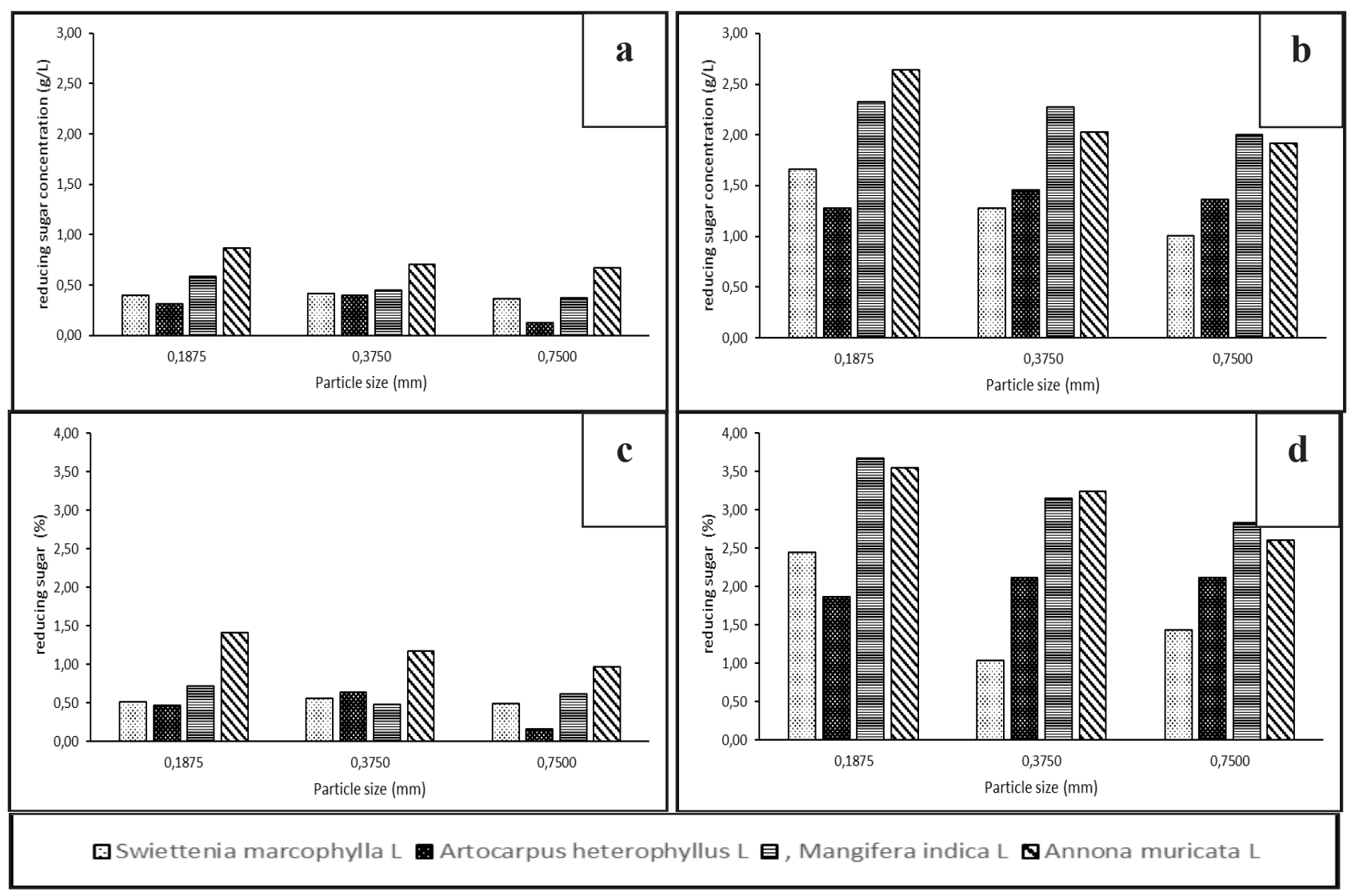

Fig. 2. The result of reducing sugar analysis, a) and c) without delignification, b) and d) with delignification

words, slightly lignin which can soluble in $\mathrm{NaOH}$. Dissolving lignin changes crystalline structure of cellulose and improve the availability to release some hemicellulose and cellulose and slightly soluble in $\mathrm{NaOH}$. This proved with average percent weight loss after delignification, $60.15 \%$, although initial lignin + ash content before delignification only $22.75 \%$. Otherwise, the smaller initial lignin content will give the highest weight loss of cellulose and hemicellulose. It also shows the function of lignin to protect cellulose from the action of reagent chemicals and microorganism.

\subsection{Hydrolysis process}

The result of this study is consistent, that is proven by increasing production of reducing sugar as a result of acid hydrolysis of plant biomass with increasing lignin removal. Acid hydrolysis was conducted on feed stock with or without delignification using $1 \% \mathrm{H}_{2} \mathrm{SO}_{4}$. Hydrolysis was converted cellulose into glucose and hemicellulose into glucose, mannose, galactose, xylose, and arabinose. Fig. 2a. and $2 \mathrm{~b}$ showed reducing sugar concentration as $\mathrm{g} / \mathrm{L}$ and percent weight to investigate the influence of delignification treatment. As a result, plant biomass with delignification almost have higher reducing sugar concentration three times than without delignification especially for Annona muricata L. Hydrolysis with delignification treatment had removed lignin by breakage the lignin bond that one of the major barriers for acid to hydrolyze cellulose and hemicellulose. Removal of lignin with alkaline improves the performance of acid to penetrate cellulose in hydrolysis process. Besides that, Fig 2a-d showed that reducing particle size makes the surface area of leaves more larger and increase chance contact between acid and cellulose. Its makes smaller particle will have higher reducing sugar concentration than the bigger one. The highest reducing sugar concentration is about $0.1875 \mathrm{~mm}$ particle leaves size.

There are some factors to understanding the effect of without delignification on hydrolysis process. The first, acid hydrolysis process is limited by lignin that will block the accessibility of acid to penetrate to cellulose. Second, lignin has ability binding with acid. Almost $70 \%$ of the total added acid can be bound to lignin after complete hydrolysis. Finally, lignin-carbohydrate limits reaction acid-cellulose on hydrolysis process. This scheme will reduce the concentration of acid to convert cellulose into glucose [25].

The yield of reducing sugar is substantially proportional to its concentration. Fig 2 shows a slightly non-linearity for both with and without delignification leaves. This is due to the difference in the volume of sugar solution that can be separated from the residual solids. In addition, Fig. $2 \mathrm{~b}$ inform that the highest reducing sugar concentration in this study was 2,642 $\mathrm{g} /$ L. It is still too small if the sugar-producing will be used as a fermentation feedstock to produce hydrogen. To 
produce hydrogen required reducing sugar concentration higher than $1 \%(10 \mathrm{~g} / \mathrm{L})$. For further study higher reducing sugar concentrations can still be obtained by improving operating conditions such as increasing the ratio of solid to Liquid, increasing acid concentration or using other acids such as $\mathrm{HCl}$ and others Using higher acid concentrations decreases the $\mathrm{pH}$, thus more chemicals are needed to neutralize the acid. This needs further studied because using large chemicals can increase cations and anions in the solution that will affect the resilience of cell membrane microorganisms in the next fermentation.

\section{Conclusion}

Pretreatment of lignocellulose and evaluation on its conversion to reducing sugar have been conducted by comparing with and without delignification. The presence of alkali treatment with $2 \% \mathrm{NaOH}$ changes the structure and removed lignin from lignocellulose in a closed reactor. Thus improve the accessibility of acid by creating pore and breaking the lignin complex. This treatment makes cellulose and hemicellulose can convert more easily than without delignification. Leaves that can be used as feedstock to produce hydrogen should have $38-49 \%$ cellulose and hemicellulose. With delignification, 2,642 $\mathrm{g} / \mathrm{L}$ was produced by acid hydrolysis. Its three times higher than without delignification on Annona muricata L.

Besides that, reducing particle size makes the surface area of leaves more larger and increase possibility contact between acid and leaves particle. It makes smaller particle have higher reducing sugar concentration than the bigger one. The highest reducing sugar concentration is about $0.1875 \mathrm{~mm}$ particle leaves size.

\section{Reference}

1. Q. Xiang, Y. Y. Lee, P. O. Pettersson, and R. W. Torget, Appl. Biochem. Biotechnol., 105-108, 50514, (2003).

2. H. Chen et al., Fuel Process. Technol., 160, 196-206, (2017).

3. B. O. Aderemi, E. Abu, B. K. Highina, Afr. J. Biotechnol., 7 (11), 1745-1752 (2008)

4. T. De Vrije, G. De Haas, G. B. Tan, E. R. P. Keijsers, and P. A. M. Claassen, Int. J. Hydrogen Energy, 27 (11-12), 1381-1390, (2002).

5. S. M. Kotay and D. Das, Bioresour. Technol., 98 (6), 1183-1190, (2007).

6. M. D. Dewi, N. Anwar, A. Widjaja, S. Winardi (2011), Prosiding Seminar Nasional Perkembangan Riset dan Teknologi di Bidang Industri ke-17, Yogyakarta, 16 Mei 2011, ISBN: 978-979-95620-7-4, Makalah TRTP-31.

7. N. Anwar, A. Widjaja, S., S. Winardi (2010), Prosiding International Seminar on Fundamental and Application on Chemical Engineering, Dept. of Chemical Engineering - Sepuluh Nopember Institute of Technology, Bali, 3-4 Nopember 2010, Makalah A005.
8. N. Anwar and S. Winardi, Pap. Present. Chem. Eng. RDK 660.284 49 Anw p, 2012, 2012.

9. T. Mori, Y. Tsuboi, N. Ishida, N. Nishikubo, T. Demura, J. Kikuchi, Sci. Rep. 5, 1-12 (2015).

10. M. Knauf, M. Moniruzzaman, Int. Sugar J. 106, 147150 (2004).

11. V. Menon, M. Rao, Prog. Energy Combust. Sci. 38, 522-550 (2012).

12. G. Salehi Jouzani, M.J. Taherzadeh, Biofuel Res. J. 2, 152-195 (2015).

13. S. Wilkinson, D. Greetham, G.A. Tucker, Biofuel Res. J. 3, 357-365 (2016).

14. K. Zhang, Z. Pei, D. Wang, Bioresour. Technol. 199, 21-33 (2016).

15. J. K. Kurian, G.R. Nair, A. Hussain, Renew. Sustain. Energy Rev. 25, 205-219 (2013).

16. R. Chandra, J. Saddler, J. Sci. Technol. For. Prod. Process. 3, 6-14 (2013).

17. C.E. Wyman, Biotechnol. Prog. 19, 254-262 (2003).

18. H. W. Blanch, B. A. Simmons, D. KleinMarcuschamer, Biotechnol. J. 6 (9), 1086-1102 (2011).

19. R. El Hage, N. Brosse, P. Sannigrahi, A. Ragauskas, Polymer Degradation and Stability 95 (6), 997-1003 (2010).

20. Q. Q. Wang, Z. He, Z. Zhu, Y. H. P. Zhang, Y. Ni, X. L. Luo, J. Y. Zhu, Biotechnol. Bioeng. 109 (2), 381$389(2012 b)$

21. G. Chatel, K. De Oliveira Vigier, and F. J. Me, Chem. Sus. Chem., 7 (10), 2774-2787, (2014).

22. Z. Liu et al., Bioresour. Technol., 135, 23-29, (2013).

23. C. Krishnan, L. D. Sousa, M. J. Jin, L. P. Chang, B. E. Dale, V. Balan, Biotechnol. Bioeng. 107 (3), 441-450 (2010).

24. Y. Zhang, Q. Li, J. Su, Y. Lin, Z. Huang, Y. Lu, G. Sun, M. Yang, A. Huang, H. Hu, Bioresour. Technol. 177, 176-181 (2015).

25.Z. Yu, H. Jameel, H. min Chang, and S. Park, Bioresour. Technol., 102 (19), 9083-9089, (2016)

26. J. Yoo, S. Alavi, P. Vadlani, V. Amanor-Boadu, Bioresour. Technol. 102, 7583-7590 (2011).

27. F. Cotana, G. Cavalaglio, A. Nicolini, M. Gelosia, V. Coccia, A. Petrozzi, L. Brinchi, Energy Proced. 45, 52-60 (2014).

28. T. Leskinen, S.S. Kelley, D.S. Argyropoulos, ACS Sustain. Chem. Eng., 3, 1632-1641 (2015).

29. A.S. Liggenstoffer, N.H. Youssef, M.R. Wilkins, M.S. Elshahed, J. Microbiol. Methods 104, 43-48 (2014).

30. S. Behera, R. Arora, N. Nandhagopal, S. Kumar, Renew. Sustain. Energy Rev. 36, 91-106 (2014).

31. Z. Chaula, M. Said, G. John, S. Manyele, C. Mhilu, Smart Grid Renew. Energy 5, 1-7 (2014).

32. Datta, R., Biotech. and Bioeng. 23 (9), 2167-2170 (1981)

33. Z. Yan, J. Li, S. Chang, T. Cui, Y. Jiang, M. Yu, L. Zhang, G. Zhao, P. Qi, S. Li, Fuel 158, 152-158 (2015).

34. E. B. Heggset, K. Syverud, K. Øyaas, Biomass Bioenergy 93, 194-200 (2016).

35. Y.-X. An, M.-H. Zong, H. Wu, N. Li, Bioresour. Technol. 192, 165-171 (2015). 